\title{
Predation has no competition: factors influencing space and resource use by echinoids in deep-sea coral habitats, as evidenced by continuous video transects
}

\author{
Stevenson Angela ${ }^{1,{ }^{*}}$, Mitchell Fraser J. G. ${ }^{1}$, Davies Jaime ${ }^{2}$ \\ ${ }^{1}$ School of Natural Sciences; Trinity College Dublin; Dublin Ireland \\ ${ }^{2}$ Ifremer; Département LEP; Centre de Brest; Plouzané France \\ * Corresponding author : Angela Stevenson, email address : stevenan@tcd.ie
}

\begin{abstract}
:
Predation and competition are highly influential factors determining space use in foraging animals, and ultimately contribute to the spatial heterogeneity observed within habitats. Here we investigated the influence of competition and predation on space and resource use via continuous video transect observations - a tool that has not previously been employed for this purpose. This study therefore also evaluates video data as a pragmatic tool to study community interactions in the deep sea. Observations were compiled from 15 video transects spanning five submarine canyons in the Bay of Biscay, France. Substrate choice, positioning on the coral, echinoid aggregate size, and the presence/absence of predators (e.g. fish and decapods) as well as competitors (both inter- and intra-specific) were recorded. Two dominant co-existing echinoid taxa, echinothurids and Cidaris cidaris (3188 total observations), were observed in the study. For the echinothurids, no significant trends were detected in the inter- and intra-specific competition data. For Cidaris cidaris, significant shifts in substrate use were correlated to the presence of inter-specific competitors (echinothurids), whereby an increase in dead coral substrate usage was observed. Highly significant patterns were detected amongst echinoids near fish and decapod predators. A shift to the base of the coral infra-structure was correlated to the presence of fish, and fewer individuals were observed in the open areas of the reef and a greater number were found in the mid and top sections of the coral when in the presence of decapods. Aggregates formed irrespective of the presence of predators. Aggregations are likely to form for feeding and reproduction rather than for defensive purposes; and migration along the coral infra-structure may be a predator-driven behaviour as echinoids seek refuge from predators. Predation risk might play a stronger - or more detectable - role in structuring echinoid space and resource use in deep-sea coral habitats. In addition, the study successfully detected patterns in the video data thereby demonstrating its potential usefulness for similar ecological studies on other deep-dwelling megabenthos.
\end{abstract}

Keywords : Aggregation, Bay of Biscay, Cidaris cidaris, community interactions, deep sea, Echinothuriidae, NE Atlantic, refuge, space use

\section{Introduction}

A principal objective in ecology is to study the factors driving spatial distribution and abundance patterns of populations, ultimately leading to the understanding of the 
observed community structure (Paine, 1974). Such factors are clear for neritic habitats where spatial differences in patterns of abundance, distribution, and behaviour have been attributed to food availability, competition, and predation (Paine, 1974; Menge and Sutherland, 1976; Sammarco, 1980; Sih et al., 1985; McClanahan, 1988; Birkeland, 1989; Rochette and Himmelman, 1996; Privitera et al., 2008; Orrock et al., 2013). In deep-sea ecology, the topic of predation and competition has received a large amount of theoretical and conceptual consideration as we strive to determine the relative importance of predation and competition in structuring deep-sea communities. These factors form the basis of two major -and conflicting- theories explaining processes structuring the deepsea faunal community and thus permitting for high species diversity. The first argues the importance of biological disturbances, such as nonselective predation, in maintaining high benthic diversity (Dayton and Hessler, 1972), whereas the second attributes it to specific competitive interactions restrained by niche diversification (Sanders, 1968; Slobodkin and Sanders, 1969; Grassle and Sanders, 1973). While analytical work has been conducted to test these hypotheses (E.g., Rex, 1976; Micheli et al., 2002; McClain, 2005; Gallucci et al., 2008a, 2008b; McClain and Barry, 2010), such studies still remain rare. As such, much debate remains regarding the role of predation and competition in structuring deep-sea communities and thus maintaining high species diversity.

Imagery from deep-sea video transects are conventionally used to map habitats and quantitatively investigate megafaunal assemblages in these environments (Smith et al., 1993; Priede and Merrett, 1998; Lampitt et al., 2001; Solan et al., 2003, Jones et al., 2007; Howell et al., 2010). They permit for a continuous observation of a wide area, which can then be used to gather information about species diversity, community assemblage, and spatial distributions (Solan et al., 2003; Jones et al., 2007; Althaus et al., 2009; Williams et al., 2010). While video transects have proven to be a powerful tool to study these aspects of deep-sea megafuanal ecology, no study has yet exploited it to investigate the relative importance of biological interactions, such as predator-prey and competitive interactions.

Ecological studies are technically challenging and/or costly to execute in deep-sea environments. Nevertheless, video data has recently become plentiful and readily available, making them an ideal resource to address questions about predator-prey and competitive interactions. Given a large enough sample size, one would expect to be able to tease out the underlying patterns within a community. Prior knowledge of such interactions between species in a community is required in order to make informed management decisions that will protect vulnerable ecosystems such as deep-sea coral habitats. These corals are incredibly important both from an ecological and economic point of view and while extensive anthropogenic damage has been observed on coldwater coral (CWC) reefs, there still exists insufficient protection for these fragile ecosystems (Koslow, 2007).

Furthermore, despite the dominant role of echinoids in neritic habitats very little is known about their behaviour in deep-sea environments. Deep-sea echinoids are not ecologically distinct from their warm-water counterparts; they are broad generalist feeders that have been observed to utilize space differently depending on the quality of the food resource available (Boolootian et al., 1959; Emson and Young, 1998; Hollertz, 2002; Stevenson 
and Rocha, 2013). Shallow-water echinoids show significant partitioning of food and space to avoid both predators and competitors (McClanahan, 1988). As such, predation risk and competitive interactions may also help shape patterns of resource use by deepsea echinoids.

Consequently, the study primarily aims to explore the relative importance of predation and competition as organizing factors for the two dominant coexisting echinoid taxa, echinothurids and Cidaris cidaris (Echinodermata: Echinoidea), found in coral habitats, using continuous video transects. It specifically investigates behavioural responses, such as space and resource use, which are defined as substrate preference and positioning on the coral infrastructure (i.e., dead and live coral reef).

\section{Predation of echinoids}

Predation pressures have a strong influence on the population structure, distribution, abundance, and behavioural adaptations of shallow-water echinoids (Carpenter, 1984; Scheibling and Hamm, 1991; Vadas and Elner, 2003). Predators of tropical coral and shallow-water temperate reef echinoids primarily consist of reef-fish species and decapods (Muntz et al., 1965; Birkeland, 1989; Scheibling, 1996; Barnes and Crook, 2001). Here, aggregative and flight responses have been proposed as prominent and effective mechanisms to reduce predation risk from such predators (see Scheibling, 1996; and Vadas and Elner, 2003).

Analytical work conducted on deep-sea communities has revealed significant positive correlations between gastropod predator diversity and overall infaunal diversity (Rex, 1976). Also, experimental work has shown that predation possesses a strong effect on the organization of infaunal assemblages (Thistle et al., 2008; Gallucci et al., 2008a, 2008b) and hydrothermal communities (Micheli et al., 2002), but the effect of predators on the behaviour of deep-sea megabenthos largely remains unknown. It is likely, however, that behavioural adaptations coincide with those observed in their shallow-water counterparts.

Inter- and intraspecific competition

Competitive interactions have been deemed a crucial player in explaining deep-sea diversity patterns (Sanders, 1968; Slobodkin and Sanders, 1969; Grassle and Sanders, 1973). For example, a minimum distance found in the morphospace of deep-sea gastropod species suggests that these gastropod communities might be structured by competition (McClain, 2005). And megabenthic disturbance by mobile deposit feeders and scavengers near submarine canyon cliff faces reinforces the importance of habitat modifiers in the deep sea (McClain and Barry, 2010). Studies directly testing this hypothesis in the deep sea are lacking, but this paradox has been thoroughly tested in shallow water echinoids. Under food-limited conditions, inter- and intraspecific competition is frequently observed and niche partitioning is common among shallowwater echinoids (Sammarco, 1980; McClanahan, 1988; McClanahan and Muthiga, 1988; Shulman, 1990; McClanahan, 1992; Privitera et al., 2008). The sypmatrically occurring taxa, Echinometra mathaei, Diadema savignyi, and Diadema setosum, are spatially specialized to avoid competition with each other (McClanahan and Muthiga, 1988). They utilize different sized burrows and crevices when avoiding predators. In experimental 
trials, Echinometra lucunter and Echinometra viridis commonly engage in agonistic interactions between conspecifics and congeners, where encounters result in pushing, biting, and subsequent conquest of a location (Shulman, 1990).

Like Echinometra and Diadema, the two deep-sea echinoid taxa under observation in the present study, echinothurids and C. cidaris, co-occur in Lophelia-Madrepora reefs and surrounding habitats (Stevenson and Rocha, 2013). Where they co-occur within Lophelia-Madrepora reefs, these echinoids preferentially feed on the coral infrastructure (i.e., dead and living reef) because it represents a potentially important and nutritious food source for echinoids (Stevenson and Rocha, 2013). While echinothurids and $C$. cidaris share these similarities in space and food resource use, it is unclear whether competition is taking place, but given that they depend on a similar food source within the same habitat then we assume that there is some degree of competition taking place for the coral resource as both food and refuge space.

The study, investigates the effects of predation (i.e., fish and decapods) and competition (i.e., inter- and intraspecific) on behavioural responses for space and resource use by the cidaroid $C$. cidaris and individuals belonging to the family Echinothuriidae. It specifically tests the null hypothesis that predation and competition have no effect on echinoid aggregation patterns and space use, such as positioning on the coral infrastructure (i.e., live and dead reef structure) and substrate use. In view of the evidence presented, (i) a greater number of echinoids observed sheltering below the coral infrastructure when in the vicinity of fish and decapod predators, (ii) aggregations are expected to form when in the presence of a predator, and (iii) fewer members of the weaker echinoid taxa are expected on the coral infrastructure when in the presence of the dominant competitor.

\section{Materials and methods}

\section{Study area}

A series of fifteen continuous video transects were collected with a vertical high definition camera of the remotely operated vehicle (ROV) Victor 6000 during the BOBECO research cruise 2011 onboard 'NO Pourquoi pas?' in the Bay of Biscay, France. Fifteen video transects (comprising $25 \mathrm{hrs}$ of video recording) were obtained from five neighboring canyons: three transects in Croisic, five in Guilvinec, three in Petit Sole, two in Crozon, and two in Morgat-Douarnenez canyons (Fig. 1). The bathymetric dataset was obtained from Bourillet et al. (2003) for Fig. 1A, D; and Bourillet et al. (2012) for Fig. 1B, C, E, F. 


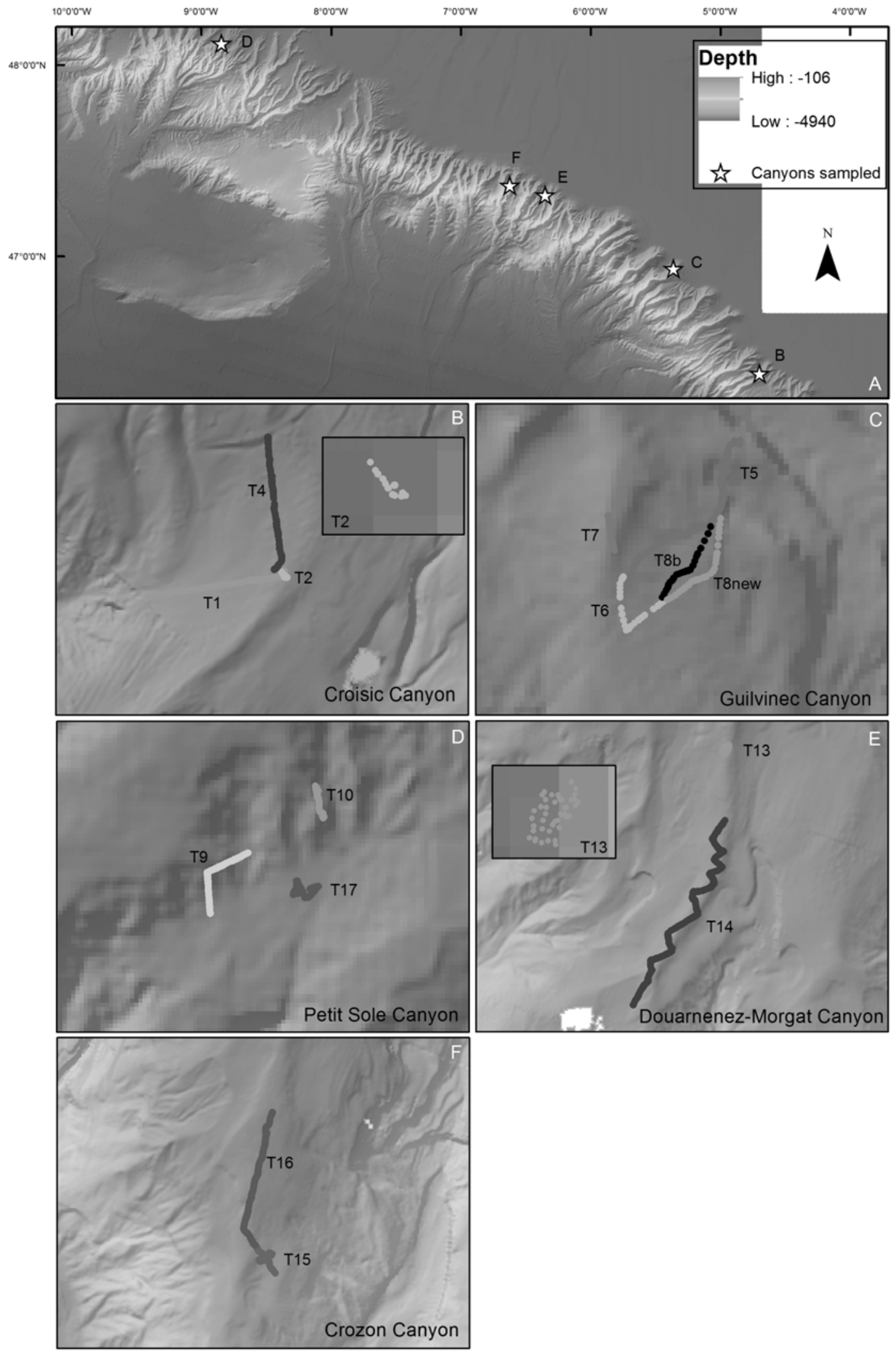


Fig. 1. Location of the study area and video transects $(\mathrm{T})$ in canyons in the Bay of Biscay, France (A). Transects T1, T2, T4 in Croisic canyon (B); T5, T6, T7, T8b, 'T8new' in Guilvinec Canyon (C); T9, T10, and T17 in Petit Sole Canyon (D); T13 and T14 in Douarnenez-Morgat Canyon (E); T15 and T16 in Crozon Canyon (F).

\section{Video survey}

Continuous video transects were obtained within adjacent canyons. Transects were nearby but never overlapping (Fig. 1). While we attempted to maintain constant ROV cruising speed $(0.5 \mathrm{kt})$ and altitude $(2 \mathrm{~m}$ from the bottom), the ROV did reach a maximum altitude of $5 \mathrm{~m}$ due to strong currents encountered in some parts of the transects. Consequently, the transects vary in width from $2 \mathrm{~m}$ to a maximum of $12 \mathrm{~m}$. Photographs where the bottom floor was obscured (from high altitude or frames that were out of focus) were excluded from the analyses.

\section{Image analyses}

To determine the influence of predation and competition on deep-sea echinoid resource use, we compared echinoid microspatial preferences in the presence and absence of $(i)$ interspecific competitors, (ii) fish, and (iii) decapod predators.

To further decipher echinoid response patterns to predators, we collected data on echinoid positioning on coral substrate (i.e., at the base/top of dead/living coral). The presence and absence of surrounding predators (fish and decapods) was noted for each video frame containing an echinoid. Predators of deep-sea echinoids are not well documented, however, Chimaera fulva and Chimaera lignaria are known to feed on deep-sea echinoids (Walker et al., 2008) and several fish taxa, such as Molva molva, Alopecephalus bairdii, Epigonus telescopus, Helicolenus dactylopterus, Chimaeras spp, and the spiny eels are known to supplement their diet with echinoderms (Howell et al., 2009). Decapods as well as octopi have also been observed predating on deep-sea echinoids (Stevenson personal observations). As such, the presence of Chimaeras spp, Molva molva, Mora moro, Lepidion spp, Trachyscorpia spp and sharks; as well as decapods Bathynectes spp, Chaceon affinis, and other unidentified crabs were noted along each transect. Note that octopi have also been observed feeding on echinoids (Stevenson personal observations), but they were excluded from this study due to the low frequency of octopi observations.

Aggregation patterns were also recorded whereby the number of conspecifics within each aggregate were counted. An 'aggregate' was defined as a loose cluster of echinoids in the vicinity of each other. With the help of physical objects in the image and the video time stamp we were able to gage the proximity of echinoids within a transect.

To determine microhabitat preferences associated with competitive interactions, the substrate immediately below each echinoid was recorded along with the presence or absence of inter- and intraspecific competitors in proximity (or within the image) of the observed echinoid. Five substrates were identified: sediment, rubble, remains, dead reef, and live coral. 
Community composition varies with depth and seafloor characteristics (Williams et al., 2010) and habitat type is a good indicator of zonation for these parameters, so analyses within habitat type were compared. Thus for each echinoid encountered we recorded the habitat type utilized. Nine categories were used in our study. Habitats characterized by coral infrastructure consisted of 'isolated colony on hard substrate', 'isolated colony on soft substrate', 'loosely-packed framework of Lophelia and/or Madrepora', 'colonized cold-water coral (CWC) reef', 'dead reef', and 'living CWC reef'; and habitats devoid or with fine, broken and low lying coral material were 'CWC rubble', 'CWC remains', and 'sediment'. These nine categories were formulated from the CoralFish Northeast Atlantic and Mediterranean Cold-Water Coral Habitats Catalogue (Guillaumont et al., 2012).

\section{Statistical analyses}

All statistical analyses were performed in R version 2.15.1 (R Core Team, 2012) with packages 'nnet' and 'MASS' (Venables and Ripley, 2002).

A multinomial generalized linear model (GLM) was used to test the significance of echinoid positioning on coral in the presence/absence of predators (i.e., fish, decapods and their interaction); the response matrix consisted of four columns (i.e., four positions: 'top', 'bottom', 'intermediate', and 'open'). 'Top' and 'bottom' which refer to the extreme top and bottom portions of the coral, respectively; and 'intermediate' heights located between these top and bottom sections; 'Open' which identifies echinoids positioned in exposed areas of coral containing habitat (i.e., on sediment, rubble, remains, but still within the coral containing habitat). Models were compared with an analysis of deviance (i.e., 'anova' function, test $=$ 'Chisq').

Note that the presence of inter- and intraspecific competitors was initially added to the model to verify whether these might affect coral positioning, but they were removed from the final predator-prey model because they showed no significant correlation with coral positioning ( $p=0.2$ and 0.3 , respectively).

Similar to the predation model, a multinomial GLM was used to test the significance of substrate use in the presence/absence of a competitor (i.e. inter- and intraspecific). The response matrix consisted of five substrates (i.e., sediment, rubble, remains, dead reef, live coral). Statistical comparisons were only conducted for loosely packed and dead CWC reef habitats. Similar comparisons could not be made for habitats of isolated colonies of Scleractinia on hard and soft substrate due to insufficient numbers $(\mathrm{N}=1)$ of cidaroids and echinothurids encountered together.

\section{Results}

\section{Predation effects on echinoid behaviour}

A total of 2,405 C. cidaris and 781 echinothurids were observed along the video transects. A significant change in space use (coral positioning in this case) by $C$. cidaris within coral containing habitats (isolated colonies of scleractinia on soft and hard substrate, dead CWC reef, loosely packed reef, colonized reef, living CWC reef) was correlated to the presence of fish $(p<0.001)$ and decapods $(p=0.003)$. More specifically, when in the vicinity of fish, cidaroids were four times less likely to be found at the top of 
the coral infrastructure; and proportionally, there were twice as many individuals observed at the base of the coral (Fig. 2). In the presence of decapods, there were four times fewer cidaroids observed in the open areas of the reef and the odds of finding cidaroids on the coral infrastructure in the presence of a decapod were twice that in their absence (Fig. 2). There were very few observations made with both predators $(\mathrm{N}=3)$ present, but during these encounters cidaroids were only found on the coral infrastructure and never in the open areas of the reef (Fig. 2). Fish and decapod effects were significant in each other's presence but their interaction effect was not (Table 1).

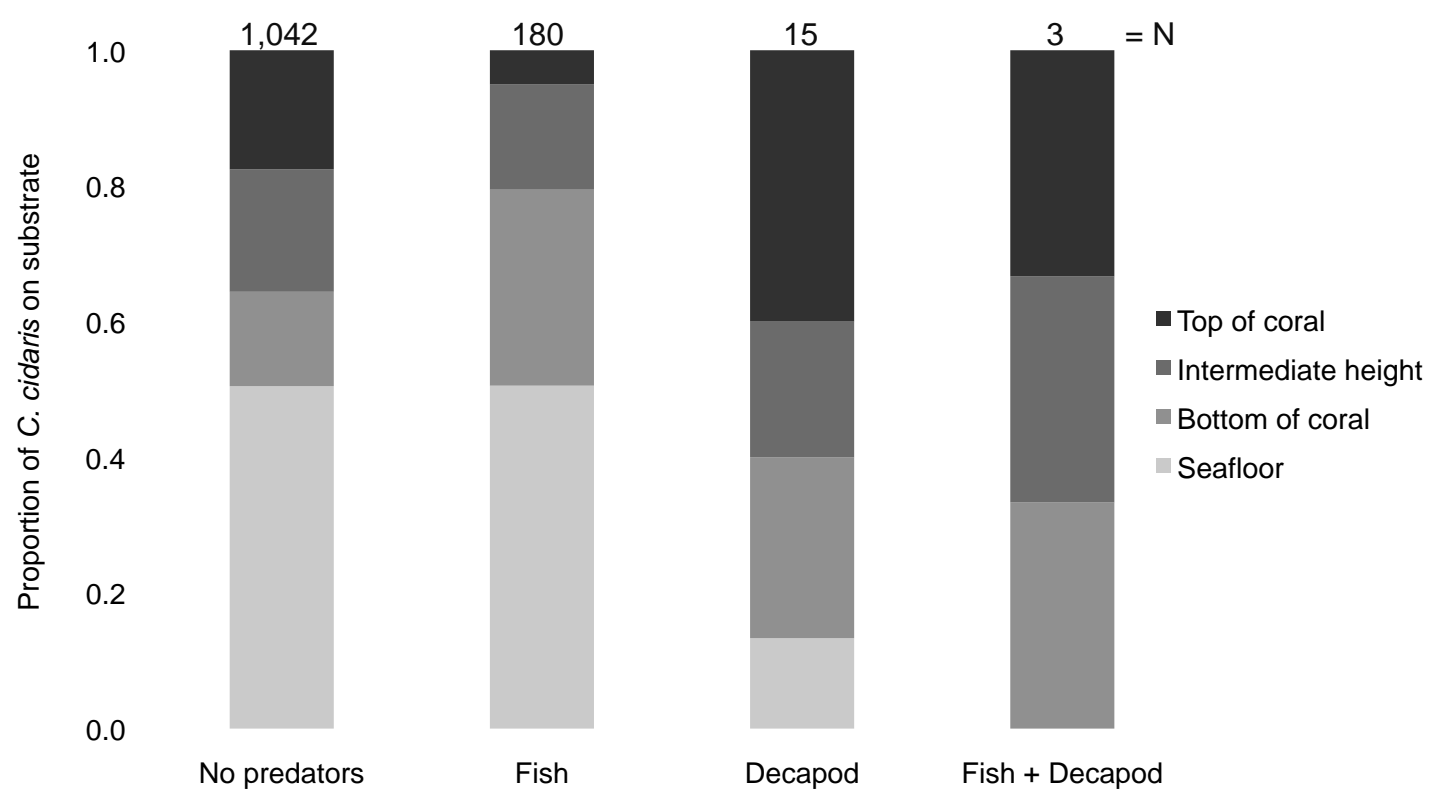

Fig. 2. Coral positioning by Cidaris cidaris in coral containing habitats when in the presence and absence of fish and decapod predators. Both the live and dead coral infrastructures were considered for coral positioning (top, intermediate, bottom heights). 'Top of coral' and 'bottom of coral' refer to the extreme top and bottom portions of the coral, respectively. Intermediate heights are located between the top and bottom sections. 'Sea floor' refers to the positioning of echinoids in exposed areas of coral containing habitats, so on sediment, rubble, remains, but still within the coral-containing habitat. $\mathrm{N}$ is the total number of individuals observed in that group.

Table 1. Effect of fish and decapod predators on space use by cidaroids in coralcontaining habitats. Results from the multinomial GLM are displayed in the table. The model tested the effect of fish, decapods, their effect in each other's presence (Models: Fish, Fish and Decapod; Decapod, Fish and Decapod), and their interaction, on C. cidaris coral positioning. Significant interactions are highlighted.

\begin{tabular}{rrrrrr}
\hline Model & $\begin{array}{c}\text { Residual } \\
\text { Df }\end{array}$ & $\begin{array}{c}\text { Residual } \\
\text { Deviance }\end{array}$ & Df & $\begin{array}{c}\text { LR } \\
\text { statistic }\end{array}$ & Pr(Chi) \\
\hline 1 & 2427 & 3065.7 & & & \\
Fish & 2424 & 3028.5 & 3 & 37.19 & $<\mathbf{0 . 0 0 1}$ \\
\hline 1 & 2427 & 3065.7 & & & \\
Decapod & 2424 & 3051.7 & 3 & 14.04 & $\mathbf{0 . 0 0 3}$ \\
\hline
\end{tabular}




\begin{tabular}{rrrrrr}
\hline Fish & 2424 & 3028.5 & & & \\
Fish and decapod & 2421 & 3014.4 & 3 & 14.12 & $\mathbf{0 . 0 0 3}$ \\
\hline Decapod & 2424 & 3051.7 & & & \\
Fish and decapod & 2421 & 3014.4 & 3 & 37.26 & $<\mathbf{0 . 0 0 1}$ \\
\hline Fish and decapod & 2421 & 3014.4 & & & \\
Fish, decapod, and their interaction & 2418 & 3012.5 & 3 & 1.94 & 0.6 \\
\hline
\end{tabular}

A significant change in coral positioning by echinothurids was correlated to the presence of fish in coral habitats $(p<0.001$; Fig. 3). In the presence of fish, there was a small decrease in echinothurids occupying the exposed areas of the coral habitat, but echinothurid positioning on the coral infrastructure showed a clear shift from the top to bottom sections of the coral. More specifically, there was a two-fold decrease in echinothurids observed at the top of the coral; none were observed at the intermediate sections, and a four-fold increase in echinothurids observed at the base of the coral when in the presence of fish (Fig. 3). In the presence of decapods, a similar trend to that of the cidaroids was observed, whereby the proportion of echinothurids encountered in exposed areas ('open') decreased, while the proportion in the top and intermediate sections of the coral infrastructure increased. However, this should be interpreted with caution as few observations were made in the presence of decapods $(\mathrm{N}=4)$, and these did not show statistical significance $(p=0.2)$.

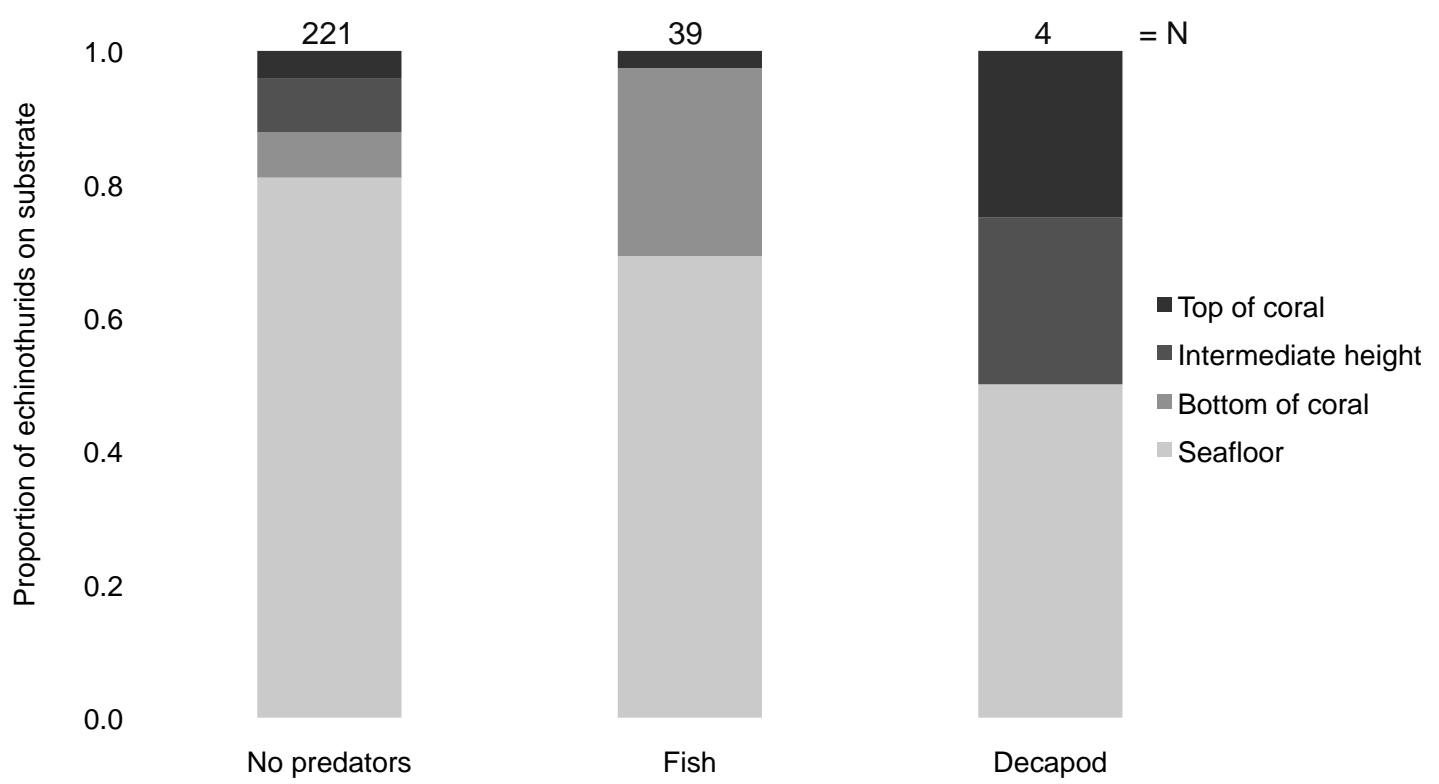

Fig. 3. Coral positioning of echinothurids in coral containing habitats when in the presence or absence of fish and decapod predators. Both the live and dead coral infrastructures were considered for coral positioning (top, intermediate, bottom heights). 'Top' and 'bottom' refer to the extreme top and bottom portions of the coral, respectively. Intermediate heights are located between the top and bottom sections. 'Open' refers to the positioning of echinoids in exposed areas of coral containing 
habitats, so on sediment, rubble, remains, but still within the coral-containing habitat. N total number of individuals observed in that group.

\section{Taxa-specific aggregation patterns in the presence/absence of predators}

Cidaroids were most frequently encountered in solitude or in pairs (Fig. 4). Large aggregates (>7 members) -with a maximum of 10 individuals- were rarely observed.

1

0.8

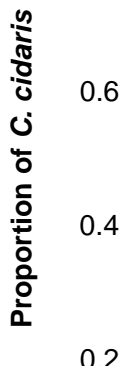

0

1

2

3

$\begin{array}{lrr}4 & 5 & 6 \\ \text { Individuals/aggregate }\end{array}$

present

absent

6

0.4

0.2

Fig. 4. Cidaris cidaris aggregative behaviour in the presence and absence of fish and decapod predators. The proportion of $C$. cidaris aggregates were pooled from all transects. Mean number of individuals per aggregate in the presence 2.22 and absence 2.07 of predators.

Echinothurids were mostly found in solitude and aggregates with $>3$ members were occasionally observed, but groups with $>6$ individuals were never encountered (Fig. 5). For both taxa, these patterns were not altered by the presence of fish (Fig. 4, 5). In fact, the average aggregate size in the presence of fish only increased slightly from that in their absence (C. cidaris: 2.22 vs. 2.07 individuals/aggregate; echinothurids: 1.39 vs. 1.13 individuals/aggregate). 


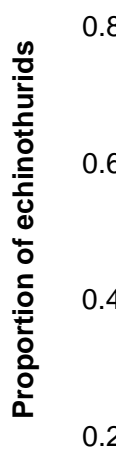

present

absent

0.6

0.4

0.2

0

1

2

3

4

5

6

Individuals/aggregate

Fig. 5. Echinothurid aggregative behaviour in the presence and absence of fish and decapod predators. Proportion of aggregates of $C$. cidaris observed along all transect. Mean number of individuals per aggregate in the presence 1.39 and absence 1.13 of a predator.

\section{Competition}

\section{Substrate utilization by echinothurids in the presence of $\mathrm{C}$. cidaris}

No significant patterns were detected for echinothurid substrate utilization in the presence of cidaroid competitors (Fig. 6; table 2). 


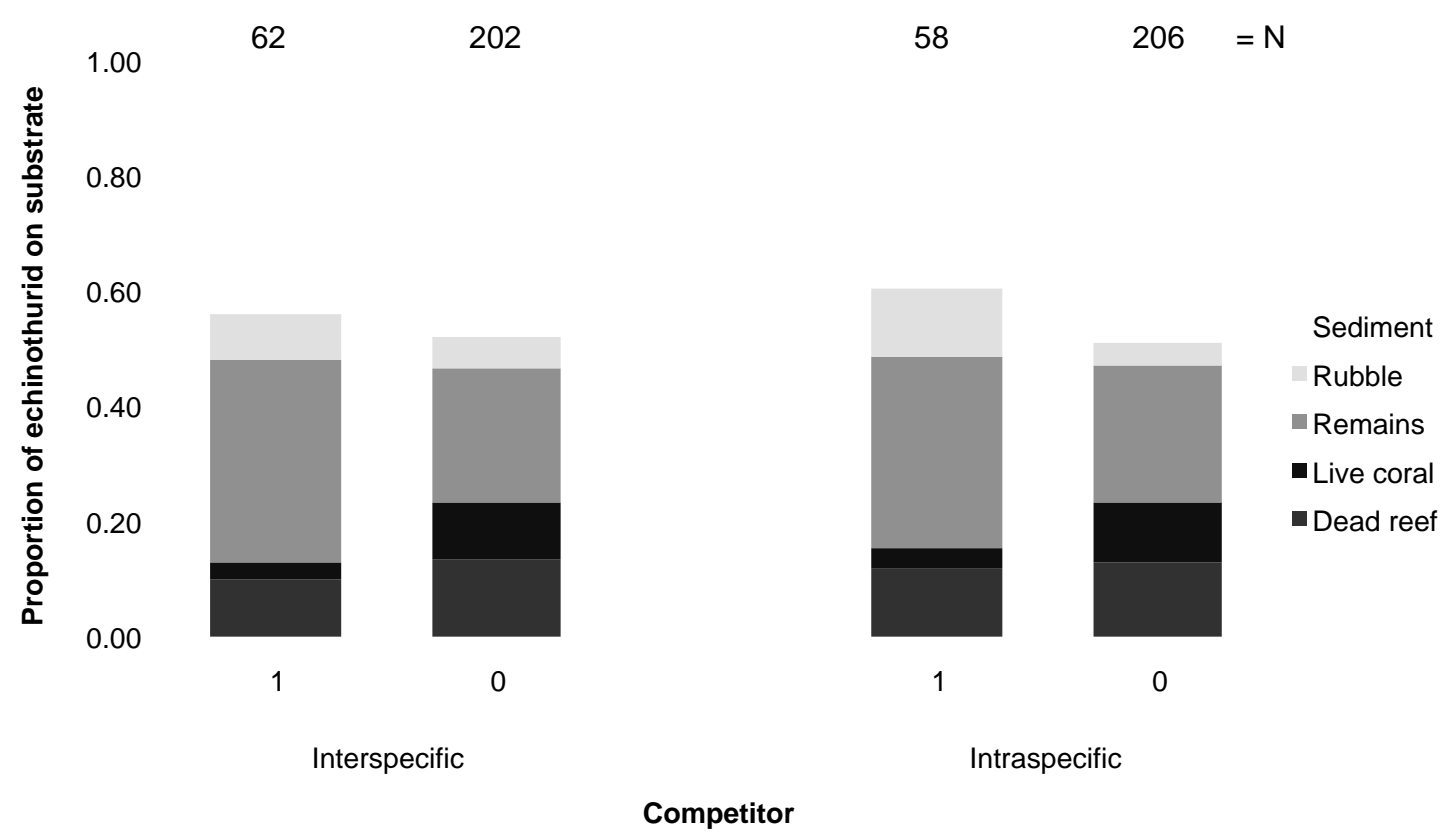

Fig. 6. Coral infrastructure usage by echinothurids in the presence (1) and absence (0) of intra- and interspecific (Cidaris cidaris) competitors. Proportions represent numbers of echinothurids on each substrates. Only habitats found containing live coral and dead reef infrastructure were included in the figure.

Table 2. Effect of inter- and intraspecific competition on echinothurid substrate use within coral containing habitats. Results from the multinomial GLM are displayed in the table. The model tested the effect of inter- and intraspecific competition, and their effect in each other's presence (Models: inter, inter and intra; intra, intra and inter), and their interaction, on echinothurid substrate choice. Inter $=$ interspecific competition (i.e. presence of Cidaris cidaris); Intra $=$ intraspecific competition (i.e. presence of other echinothurids). Significant interactions are highlighted.

\begin{tabular}{rccccc} 
Model & $\begin{array}{c}\text { Residual } \\
\text { Df }\end{array}$ & $\begin{array}{c}\text { Residual } \\
\text { Deviance }\end{array}$ & Df & $\begin{array}{c}\text { LR } \\
\text { statistics }\end{array}$ & Pr(Chi) \\
\hline 1 & 908 & 689.4 & & & \\
Intra & 904 & 675.8 & 4 & 9.60 & 0.05 \\
\hline 1 & 908 & 689.3 & & & \\
Inter & 904 & 681.7 & 4 & 7.62 & 0.1 \\
\hline Intra & 904 & 679.8 & & & \\
Intra and inter & 900 & 673.8 & 4 & 5.93 & 0.2 \\
Inter & 904 & 681.7 & & & \\
Intra and inter & 900 & 673.8 & 4 & 7.91 & 0.1 \\
\hline Intra and inter & 900 & 673.8 & & & \\
Intra, inter, and their interaction & 896 & 668.9 & 4 & 4.98 & 0.3 \\
\hline
\end{tabular}

Substrate utilization by Cidaris cidaris in the presence of echinothurids

A significant shift in substrate use by cidaroids was correlated to the presence of interspecific (echinothurids), but not intraspecific competitors (Fig. 7; table 3). Cidaroids 
showed a two-fold increase in dead coral infrastructure usage when in the presence of echinothurids; no change of remains substrate usage; a slight decrease in live coral and sediment substrate utilization; and no cidaroids were observed on rubble.

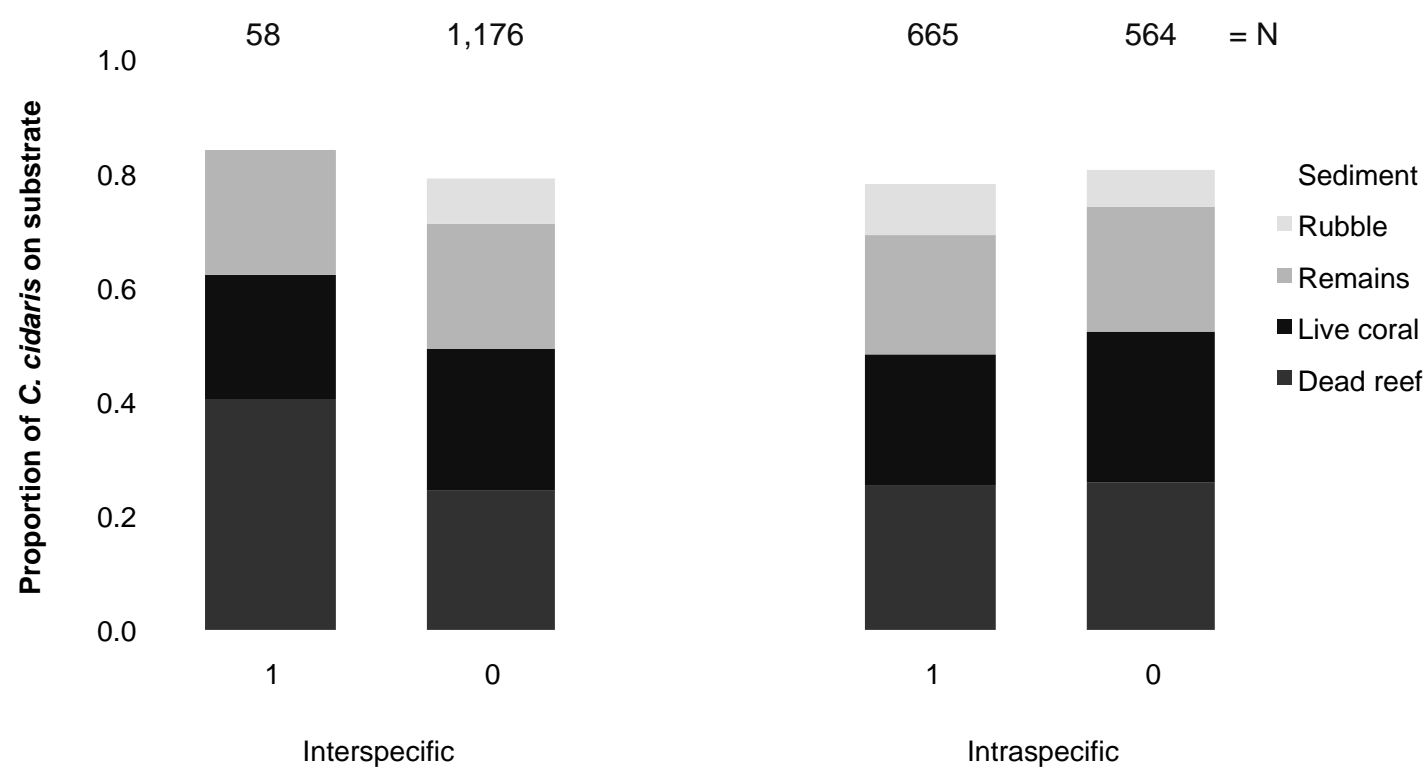

\section{Competitor}

Fig. 7. Coral infrastructure usage by Cidaris cidaris in the presence (1) and absence (0) of intra- and interspecific (echinothurid) competitors. Proportions represent numbers of cidaroids on each substrate. Only habitats found containing live coral were included in the figure.

Table 3. Effect of inter- and intraspecific competition on cidaroid substrate use within coral containing habitats. Results from the multinomial GLM (analyzed in the R package) are displayed in the table. The model tested the effect of inter- and intraspecific competition, and their effect in each other's presence (Models: inter, inter and intra; intra, intra and inter), and their interaction, on Cidaris cidaris substrate choice. Inter = interspecific competition (i.e. presence of echinothurids); Intra $=$ intraspecific competition (i.e. presence of other cidaroids). Significant interactions are highlighted.

\begin{tabular}{rccccc}
\hline Model & $\begin{array}{c}\text { Residual } \\
\text { Df }\end{array}$ & $\begin{array}{c}\text { Residual } \\
\text { Deviance }\end{array}$ & Df & $\begin{array}{c}\text { LR } \\
\text { statistics }\end{array}$ & Pr(Chi) \\
\hline 1 & 3236 & 3835.1 & & & \\
Intra & 3232 & 3827.4 & 4 & 7.67 & 0.1 \\
\hline 1 & 3236 & 3835.1 & & & \\
Inter & 3232 & 3822.4 & 4 & 12.70 & $\mathbf{0 . 0 1}$ \\
\hline Intra & 3232 & 3827.4 & & & \\
Intra and inter & 3228 & 3815.5 & 4 & 11.97 & $\mathbf{0 . 0 2}$ \\
\hline Inter & 3232 & 3822.4 & & & \\
Intra and inter & 3228 & 3815.5 & 4 & 6.95 & 0.1 \\
\hline Intra and inter & 3228 & 3815.5 & & & \\
Intra, inter, and their interaction & 3224 & 3805.3 & 4 & 10.14 & $\mathbf{0 . 0 4}$ \\
\hline
\end{tabular}




\section{Discussion}

\section{Behavioural responses to predators}

Cidaroids and echinothurids were found at all levels on the coral substrate (extreme top and bottom as well as intermediate heights) when in the absence of fish predators, but when in the presence of fish, a clear shift from the top and intermediate to the bottom sections of the coral was observed. This suggests that echinoids might avoid these parts of the coral infrastructure when under predation threat by fish and might predominantly seek shelter at the base of the coral structure. The behavioural response observed in the presence of echinivorous decapods differed slightly to that in the presence of fish. Here, echinoids from both taxa were most often encountered on the coral infrastructure and infrequently observed in the exposed areas of the reef, suggesting that echinoids might escape decapod predation by migrating up the coral infrastructure -away from the ground- to remain out of reach from decapods.

The correlation between predators and positioning on the coral infrastructure is unlikely to be a response to currents or food availability since food availability on the coral infrastructure (i.e., associated organisms on the dead infrastructure or mucus lining the surface of live coral) is unlikely to differ in significant amounts along the height of the coral. As well, the significant change in echinoid positioning on the coral infrastructure in the presence of a predator suggests that this is most likely an artifact of predator avoidance rather than a foraging behaviour. Ebling et al. (1966), Dance (1987), Kitching (1987), and Barnes and Crook (2001) found similar predator-driven migratory patterns to the tops of boulders in populations of the shallow-water echinoid Paracentrotus lividus. Cowen (1983), Harrold and Reed (1985) and Mann (1985) found predator avoidance to be the dominant behaviour whereby echinoids remained in hiding when food was abundant and competition was minimal.

Most studies argue that predation tends to elicit a flight response in shallow-water echinoids, but others postulate that defensive aggregates are also a feasible behavioural shift resulting from predation threat (see Scheibling, 1996; and Vadas and Elner, 2003). Experimental studies have found predators to be a major contributor to conspecific aggregation in the presence of a predator (see Pearse and Arch, 1969; Bernstein et al., 1981, 1983; Scheibling and Hamm, 1991), but such defensive aggregates were not observed in our study. When comparing aggregation patterns in video frames containing predators to those without, it was found that aggregates formed irrespective of the presence of predators. When aggregates were observed, these did not appear to be associated with the presence of predators; large aggregates of echinoids formed most often when there were no predators in the vicinity and solitary individuals were often encountered in the presence of predators. In fact, large aggregates were rarely observed in our study; numbers never exceeded 10 individuals per aggregate, suggesting that aggregation isn't a common behaviour of deep-sea echinoids. Also, there was no difference between the aggregation patterns detected in habitats where spatial refuge was available over those that were absent (e.g. aggregates were as frequent in dead, colonized, and living CWC reefs vs. sediment, rubble and remains habitats). 
Vadas et al. (1986) found a similar response, where conspecific aggregations were unaltered by the presence of predators. They argue that aggregates are an artifact of feeding rather than a defense against predators. Similarly, Scheibling and Hamm (1991) showed that populations of Strongylocentrotus droebachiensis (both juvenile and adult size classes) formed exposed feeding aggregates irrespective of the presence or absence of predators; and aggregations of Lytechinus variegates only form around food or food with predators (Vadas and Elner; 2003). However, the aforementioned studies conflict with those of Bernstein et al. (1981, 1983) who found that large echinoids tend to aggregate when in the presence of predators such as crabs. Pearse and Arch (1969) also argue that Diadema setosum forms aggregates for protection against predators. Feeding (Boolootian et al., 1959) and seasonal breeding (Young et al., 1992) aggregates have also been documented among deep-sea echinoids, but -in agreement with the present studythere is no mention of defensive aggregates in the deep sea. It is possible that associative modes are also employed for protection by deep-sea echinoids, but the dispersed and sparse echinoid densities observed in the study render common defense ineffective in the submarine canyons of the Bay of Biscay. By expanding the study over a broader geographic scale we may be able to compare denser populations such as those found in the southwest Pacific, and thus better understand factors influencing aggregation patterns in deep environments.

Experimental work conducted in the deep sea supports the notion that predators have a strong structuring role on the benthic invertebrate fauna (Rex, 1976; Micheli et al., 2002; Gallucci et al., 2008a, 2008b; Thistle et al., 2008). Rex (1976) argues that predators are a key factor in biological accommodation in the deep sea and that this contribution is largely depth dependent. Likewise, Micheli et al. (2002) suggest that large epibenthic predators influence hyrdothermal vent communities by regulating the activities of small mobile grazers and thus influence the structure of these communities through chains of species interactions. It is by this same logic that the predators (fish and decapods) in the present study might influence the organization of echinoids in deep-sea coral reef habitats and subsequently affect the chain of interactions between echinoids and their competitors or prey. While this might not directly explain the high species diversity observed in deepsea benthos, it does indirectly provide support for Dayton and Hessler's (1972) hypothesis, which highlights the importance of predation in structuring communities and hence promote high species diversity in the deep sea.

Overall, sheltering from predators has been shown to be an effective avoidance tactic for echinoids in shallow-water systems (Ebling et al., 1966; Carpenter, 1984; Vadas et al., 1986; Dance, 1987; Kitching, 1987; Scheibling and Hamm, 1991; Barnes and Crook, 2001; Hagen et al., 2002). The absence of an obvious trend in aggregation numbers, and the strong correlation between predator and substrate positioning in the present study suggests that deep-sea echinoids in the submarine canyons of the Bay of Biscay may also respond to predators by becoming more cryptic (i.e., in this case, hiding at the base of the coral substrate) rather than aggregating for protection.

Behavioural responses to inter-and intraspecific competition 
Experimental work directly testing the hypothesis of competitive interactions as a structuring force for deep-sea communities are largely lacking, but several studies have attributed observed deep-sea diversity patterns to such interactions (Sanders, 1968; Slobodkin and Sanders, 1969; Grassle and Sanders, 1973; McClain, 2005; McClain and Barry, 2010). McClain (2005) explains that the minimum distance found in the morphospace of deep-sea gastropod species suggests that these gastropod communities might be structured by competition. And megabenthic disturbance by mobile deposit feeders and scavengers near submarine canyon cliff faces reinforces the importance of habitat modifiers in the deep sea (McClain and Barry, 2010). The findings of the present study only partly agree with those of the aforementioned studies on competitive interactions in the deep sea. While no significant trends in intra- and interspecific competition were detected for echinothurids, significant patterns did emerge for cidaroid interactions with their interspecific competitors. A shift towards dead reef substrate usage was correlated with the presence of echinothurids suggesting that there might be a correlation between cidaroid substrate choice and interspecific competition. However, we were perplexed by the lack of a corresponding shift by echinothurids. Live and dead coral infrastructure is thought to be a nutritionally valuable resource for deep-sea echinoids (Stevenson and Rocha, 2013) that might drive competitive interactions. If cidaroids were to show competitive dominance for this resource over echinothruids, then we would have expected to see a response by echinothurids when in reality there seemed to be no correlation between echinothurids and their interspecific competitors (cidaroids in this case).

The observed correlation might be better explained by teasing out the patterns within specific habitats. Where nutritious resources were available, such as living CWC reef, loosely packed, and dead reefs, there was a change in substrate usage by echinothurids in the presence of a competitor (i.e., C. cidaris). Fewer echinothurids were observed on the coral infrastructure (dead and live combined) in the presence of $C$. cidaris. McClanahan (1988) observed competitive hierarchy between three coexisting species of shallow-water echinoids that shared similar diets and a broad within-habitat distribution, but these species differed in their microspatial preferences. Such patterns were also observed by Privitera et al. (2008) who found coexistence via food resource partitioning by Paracentrotus lividus and Arbacia lixula in the infralittoral zones of the Mediterranean and NE Atlantic. In our study, similar patterns of hierarchal structuring as well as coexistence due to microhabitat and diet diversification among deep-sea echinoids were obscured by anomalous patterns and insignificant correlations. Further investigation is required in order to disambiguate the role of competition in deep-sea coral habitats.

Alternately, the lack of significance might be attributed to factors such as small population size. According to Menge and Sutherland (1976) competition tends to regulate community structure only once it approaches or has reached its carrying capacity, only then do the species in that community actually compete. It is possible that competition might not be an influential factor for echinoid space and resource use in the submarine canyons of the Bay of Biscay, whereby echinoid numbers might be too low for any competition to take place.

\section{Limitations of the study and directions for future research}


It is pertinent to consider the dispersion effect that an ROV might have on benthopelagic fish. Nearby fish might be attracted or repelled by the lights of the camera and thus possibly interfere with the outcomes of the study. Few studies have investigated this issue, however, Cailliet et al (1999) compared different methods for observing deep-sea fish. Trawls, camera sleds, and submersibles were compared for benthic habitats. Here, submersibles detected similar fish taxa and density as trawls and sleds. It is also worthwhile noting that deep-sea fish do present behavioural responses to the noise and light produced by ROVs (Lorance and Trenkel, 2006; Uiblein, 2011). Lorance and Trenkel (2006) observed the behavioural changes of several fish including Chimaeridae and Trachyscorpia spp -two taxa important to the present study- and showed a change from their natural stationary or a slow moving position to nervous control movements and lateral avoidance. Some fish sat and waited (one species), others remained active and continued to engage in bottom hunting (three taxa), while others displayed little activity in their bottom habitat (three taxa). While fish reactions to anthropogenic cues clearly alter their natural behaviour, the fish reportedly remain within the field of view, which is a key factor required in the present study. However, it is clear that the feasibility of ecological studies similar to the present study are highly dependent on prior understanding of animal behaviour. It is possible that certain taxa flee from the site before entering the field of view and may become an issue when conducting behavioural studies (Uiblein, 2011).

Often predation mediates coexistence of echinoid taxa via predation on the competitive dominant (McClanahan, 1988). The interplay between predation and competition has yet to be investigated. For example, McClanahan (1988) found coexistence possible between the top echinoid competitor Echinometra mathaei and its subordinate Diadema savignyi and Diadema setosum. E. mathaei was consistently ranked as the top competitor for crevice space, however high predation rates were found for E. mathaei while low rates were found on the coexisting Diadema spp. Given that predation played a significant role over competition in our study, perhaps predation might play a similar role in mediating the coexistence of the seemingly competitive dominant cidaroids and less dominant echinothurids. Laboratory based experimental work will help refine our understanding of behavioural responses resulting from these interactions.

\section{Conclusions}

While our study was purely observational, trends drawn from a large sample size $(3,188$ echinoids) suggest that space and resource use may be predominantly predator-driven and thus supports Dayton and Hessler's (1972) predation hypothesis for the remarkably high species diversity in the deep sea. The behavioural shift depicted in our study suggests that cripsis might be the dominant defensive function for deep-sea echinoids. We argue that the taxa in the submarine canyons studied may predominantly utilize flight responses, rather than an aggregative behaviour, to reduce predation risk. Thus aggregations are likely to form for feeding or breeding rather than for defensive purposes. Interspecific competition may influence species-specific hierarchy on nutritiously valuable substrates in the deep-sea, but the lack of statistical significance in these trends warrants further investigation in order to disambiguate the role of competition in deep-sea coral habitats. From this it is clear that understanding factors affecting space use and interactions by 
deep-sea megabenthos may help us tease out the underlying mechanisms regulating deepsea community structure and thus contribute to important concepts such as the paradox of high deep-sea diversity. Most importantly, the study has shown that video data may serve a useful role in discerning the relative importance of these interactions in deep-sea environments, which are necessary for gaining a better understanding of the ecological processes taking place in vulnerable deep-sea habitats, such as coral reefs.

\section{Acknowledgements}

We thank the pilots of ROV Victor 6000, captain and crew of RV Pourquoi Pas? for their support in seagoing operations. Thanks are also due to the chief scientist Dr. Sophie Arnaud-Haond (RV Pourquoi Pas?, BOBECO cruise 2011), for successfully organizing and facilitating our work during the three cruises. Also, we are grateful for the advice of Dr. Scott Foster, Mrs. Franzis Althaus, and two anonymous reviewers who provided helpful comments on the early draft of the manuscript. This study was partly funded by the Explorers Club 2011 Exploration award and the Irish Research Council EMBARK postgraduate scholarship to A. Stevenson and by the EC FP7 project 'CoralFISH' under grant agreement no. 213144.

\section{References}

Althaus F., Williams A., Schlacher T., Kloser R., Green M., Barker B., Bax N., Brodie P., Schlacher-Hoenlinger M. (2009) Impacts of bottom trawling on deep-coral ecosystems of seamounts are long-lasting. Marine Ecology Progress Series, 397, 279294.

Barnes D., Crook A. (2001) Quantifying behavioural determinants of the coastal European sea-urchin Paracentrotus lividus. Marine Biology, 138, 1205-1212.

Bernstein B., Williams B., Mann K. (1981) The role of behavioral responses to predators in modifying urchins' (Strongylocentrotus droebachiensis) destructive grazing and seasonal foraging patterns. Marine Biology, 63, 39-49.

Bernstein B.B., Schroeter S.C., Mann K.H. (1983) Sea urchin (Strongylocentrotus droebachiensis) aggregating behavior investigated by a subtidal multifactorial experiment. Canadian Journal of Fisheries and Aquatic Sciences, 40, 1975-1986.

Birkeland C. (1989) The influence of echinoderms on coral-reef communities. In: M. Jangoux \& J.M. Lawrence (Eds.) Echinoderm studies. Rotterdam: A. A. Balkema.

Boolootian R., Giese A., Tucker J., Farmanfarmaian A. (1959) A contribution to the biology of a deep sea echinoid, Allocentrotus fragilis (Jackson). Biological Bulletin, 116, 362-372.

Bourillet J-F., Reynaud J.-Y., Baltzer A. and Zaragosi S. (2003). "The "Fleuve Manche": the sub-marine sedimentary features from the outer shelf to the deep-sea fans." Journal of Quaternary Science 18(3-4): 261-282. 
Bourillet J-F. (Coord.), de Chambure L. and Loubrieu B. (2012). Sur les traces des coraux d'eau froide du golfe de Gascogne. 8 cartes bathymorphologiques et géomorphologiques au 1/100.000, Ifremer et Quae (Ed.).

Cailliet G.M., Andrews A.H., Wakefield W.W., Moreno G., Rhodes K.L. (1999) Fish faunal and habitat analyses using trawls, camera sleds and submersibles in benthic deepsea habitats off central California. Oceanologica Acta, 22, 579-592.

Carpenter R. (1984) Predator and population density control of homing behavior in the Caribbean echinoid Diadema antillarum. Marine Biology, 82, 101-108.

Cowen R.K. (1983) The effect of sheephead (Semicossyphus pulcher) predation on red sea urchin (Strongylocentrotus franciscanus) populations: an experimental analysis. Oecologia (Berl.), 58, 249-255.

Dance C. (1987) Patterns of activity of the sea urchin Paracentrotus lividus in the Bay of Port-Cros (Var, France, Mediterranean). Marine Ecology, 8, 131-142.

Dayton P., Hessler R. (1972) Role of biological disturbance in maintaining diversity in the deep sea. Deep Sea Research and Oceanographic Abstracts, 199-208.

Ebling F., Hawkins A., Kitching J., Muntz L. Pratt V. M. (1966) The ecology of Lough Ine XVI. Predation and diurnal migration in the Paracentrotus community. Journal of Animal Ecology, 559-566.

Emson R., Young C. (1998) Form and function of the primary spines of two bathyal echinothuriid sea urchins. Acta Zoologica, 79, 101-111.

Gallucci F., Sauter E., Sachs O., Klages M., Soltwedel T. (2008a). Caging experiment in the deep sea: Efficiency and artefacts from a case study at the Arctic long-term observatory HAUSGARTEN. Journal of Experimental Marine Biology and Ecology, 354, 39-55.

Gallucci F., Fonesca G., Soltwedel T. (2008b) Effects of megafauna exclusion on nematode assemblages at a deep-sea site. Deep Sea Research Part I: Oceanographic Research Papers, 55, 332-349.

Grassle J., Sanders H.L. (1973) Life histories and the role of disturbance. Deep Sea Research and Oceanographic Abstracts, 643-659.

Guillaumont B., Tempera F., Vertino A., Ólafsdóttir S.H, Grehan A., Smith C., Fossa J.H., Davies J., Van Den Beld I., Savini A., Rengstorf A. (2012) Northeast Atlantic and Mediterranean Cold-Water Coral Habitats Catalogue.

Hagen N.T., Andersen A., Stabell O.B. (2002) Alarm responses of the green sea urchin, Strongylocentrotus droebachiensis, induced by chemically labeled durophagous predators and simulated acts of predation and simulated acts of predation. Marine Biology, 140, 365-374.

Harrold C., Reed D. (1985) Food availability, sea urchin grazing, and kelp forest 
community structure. Ecology, 66, 1160-1169.

Hollertz K. (2002) Feeding biology and carbon budget of the sediment-burrowing heart urchin Brissopsis lyrifera (Echinoidea: Spatangoida). Marine Biology, 140, 959-969.

Howell K. L., Heymans J.J., Gordon J.D.M., Duncan J., Ayers M., Jones E.G. (2009) DEEPFISH Project: Applying an ecosystem approach to the sustainable management of deep-water fisheries. Part 1: Development of the Ecopath with Ecosim model. Scottish Association for Marine Science, Oban. U.K.

Howell K.L., Davies J.S., Narayanaswamy B.E. (2010) Identifying deep-sea megafaunal epibenthic assemblages for use in habitat mapping and marine protected area network design. Journal of the Marine Biological Association of the United Kingdom, 90, 33-68.

Jones D.O.B., Bett B.J. Tyler P.A. (2007) Megabenthic ecology of the deep FaroeShetland channel: a photographic study. Deep Sea Research Part I: Oceanographic Research Papers, 54, 1111-1128.

Kitching J.A. (1987) Ecological studies at Lough Hyne. Advances in Ecological Research, 7, 115-186.

Koslow T. (2007) The silent deep. The University of Chicago Press, London: 270pp.

Lampitt R., Bett B., Kiriakoulakis K., Popova E., Ragueneau O., Vangriesheim A., Wolff G. (2001) Material supply to the abyssal seafloor in the Northeast Atlantic. Progress in Oceanography, 50, 27-63.

Lorance P., Trenkel V.M. (2006) Variability in natural behaviour, and observed reactions to an ROV, by mid-slope fish species. Journal of Experimental Marine Biology and Ecology, 332, 106-119.

Mann K.H. (1985) Invertebrate behaviour and the structure of marine benthic communities. In: R.M. Sibley \& R.H. Smith (Eds.) Behavioural ecology. Blackwell Scientific Publications, Oxford: 227-246.

McClain C.R. (2005) Bathymetric patterns of morphological disparity in deep-sea gastropods from the western north Atlantic basin. Evolution, 59, 1492-1499.

McClain C.R., Barry J.P. (2010) Habitat heterogeneity, disturbance, and productivity work in concert to regulate biodiversity in deep submarine canyons. Ecology, 91, 964976.

McClanahan T.R. (1988) Coexistence in a sea urchin guild and its implications to coral reef diversity and degradation. Oecologia, 77, 210-218.

McClanahan T. (1992) Resource utilization, competition, and predation: a model and example from coral reef grazers. Ecological Modelling, 61, 195-215.

McClanahan T.R., Muthiga N.A. (1988) Changes in Kenyan coral reef community structure and function due to exploitation. Hydrobiologia, 166, 269-276. 
Menge B.A., Sutherland, J.P. (1976) Species diversity gradients: synthesis of the roles of predation, competition, and temporal heterogeneity. American Naturalist, 351-369.

Micheli F., Peterson C.H., Mullineaux L.S., Fisher C.R., Mills S.W., Sancho G., Johnson G.A., Lenihan H.S. (2002) Predation structures communities at deep-sea hydrothermal vents. Ecological Monographs, 72, 365-382.

Muntz L., Ebling F.J., Kitching J.A. (1965) The ecology of Lough Ine. XIV. Predatory activity of large crabs. Journal of Animal Ecology, 35, 315- 329.

Orrock J.L., Preisser E.L., Grabowski J.H., Trussell G.C. (2013) The cost of safety: refuges increase the impact of predation risk in aquatic systems. Ecology, 94, 573-579.

Paine R. (1974) Intertidal community structure: experimental studies on the relationship between a dominant competitor and its principal predator. Oecologia, 15, 93-120.

Pearse J., Arch S. (1969) The aggregation behavior of Diadema (Echinodermata, Echinoidea). Micronesica, 5, 165-171.

Privitera D., Chiantore M., Mangialajo L., Glavic N., Kozul W., Cattaneo-Vietti R. (2008) Inter-and intra-specific competition between Paracentrotus lividus and Arbacia lixula in resource-limited barren areas. Journal of Sea Research, 60, 184-192.

Priede I., Merrett N. (1998) The relationship between numbers of fish attracted to baited cameras and population density: Studies on demersal grenadiers Coryphaenoides (Nematonurus) armatus in the abyssal NE Atlantic Ocean. Fisheries Research, 36, 133137.

R Core Team (2012). R: A language and environment for statistical computing. R Foundation for Statistical Computing, Vienna, Austria. ISBN 3-900051-07-0, URL http://www.R-project.org/.

Rex M.A. (1976) Biological accommodation in the deep-sea benthos: comparative evidence on the importance of predation and productivity. Deep Sea Research and Oceanographic Abstracts, 975-987.

Rochette R., Himmelman J.H. (1996) Does vulnerability influence trade-offs made by whelks between predation risk and feeding opportunities? Animal Behaviour, 52, 783794.

Sanders H.L. (1968) Marine benthic diversity: a comparative study. American Naturalist, 102, 243-282.

Sammarco P.W. (1980) Diadema and its relationship to coral spat mortality: grazing, competition, and biological disturbance. Journal of Experimental Marine Biology and Ecology, 45, 245-272.

Scheibling R., Hamm J. (1991) Interactions between sea urchins (Strongylocentrotus droebachiensis) and their predators in field and laboratory experiments. Marine Biology, 110, 105-116. 
Scheibling R. (1996) The role of predation in regulating sea urchin populations in eastern Canada. Oceanologica Acta, 19, 421-430.

Shulman M. (1990) Aggression among sea urchins on Caribbean coral reefs. Journal of Experimental Marine Biology and Ecology, 140, 197-207.

Sih A., Crowley P., McPeek M., Petranka J., Strohmeier K. (1985) Predation, competition, and prey communities: a review of field experiments. Annual Review of Ecology and Systematics, 16, 269-311.

Slobodkin L.B., Sanders H.L. (1969) On the contribution of environmental predictability to species diversity. Brookhaven Symposia in Biology, 22, 82-92.

Smith Jr K., Kaufmann R., Wakefield W. (1993) Mobile megafaunal activity monitored with a time-lapse camera in the abyssal North Pacific. Deep Sea Research Part I: Oceanographic Research Papers, 40, 2307-2324.

Solan M., Germano J.D., Rhoads D.C., Smith C., Michaud E., Parry D., Wenzhöfer F., Kennedy B., Henriques C., Battle E. (2003) Towards a greater understanding of pattern, scale and process in marine benthic systems: a picture is worth a thousand worms. Journal of Experimental Marine Biology and Ecology, 285, 313-338.

Stevenson A., Rocha C. (2013) Evidence for the bioerosion of deep-water corals by echinoids in the Northeast Atlantic. Deep Sea Research Part I: Oceanographic Research Papers, 71, 73-78.

Thistle D., Eckman J.E., Paterson G.L. (2008) Large, motile epifauna interact strongly with harpacticoid copepods and polychaetes at a bathyal site. Deep Sea Research Part I: Oceanographic Research Papers, 55, 324-331.

Uiblein F. (2011) Deep-sea fish behavioral responses to underwater vehicles: differences among vehicles, habitats and species. In: N.A. Cruz (Ed.) Autonomous Underwater Vehicles. InTech, Rijeka, Croatia: 225-238.

Vadas R.L., Elner R.W. (2003) Responses to predation cues and food in two species of sympatric, tropical sea urchins. Marine Ecology, 24, 101-121.

Vadas R.I., Elner R.W., Garwood P.E., Babb I.G. (1986) Experimental evaluation of aggregation behavior in the sea urchin Strongylocentrotus droebachiensis. A reinterpretaion. Marine Biology, 90, 433-448.

Venables W.N., Ripley, B.D. (2002) Modern Applied Statistics with S. Fourth Edition. Springer, New York. ISBN 0-387-95457-0.

Walker T.I., Stevens J.D., Braccini J.M., Daley R.J., Huveneers C., Irvine S.B., Bell J.D., Tovar-Avila J., Trinnie F.I., Philips D.T., Treloar M.A., Awruck C.A., Gason A.S., Salini, J., Hamlett W.C. (2008) Rapid assessment of sustainability for ecological risk of shark and other chondrichthyan bycatch species taken in the Southern and Eastern Scalefish and Shark Fishery. Fisheries Research and Development Corporation Report No. 2002/033. (July 2008) 
Williams A., Schlacher T.A., Rowden A.A., Althaus F., Clark M.R., Bowden D.A., Stewart R., Bax N.J., Consalvey M., Kloser R.J. (2010) Seamount megabenthic assemblages fail to recover from trawling impacts. Marine Ecology, 31, 183-199.

Young C.M., Tyler P.A., Cameron J.L., Rumrill S. (1992) Seasonal breeding aggregations in low density populations of the bathyal echinoid Stylocidaris lineata. Marine biology, 113, 603-612. 